\title{
A pooled analysis of molecularly targeted agents for treatment of metastatic oesophago-gastric cancer in elderly patients
}

\author{
Hui Lv, Qing-Hua Zhou, Dian-Sheng Zhong
}

Department of Oncology, Tianjin Medical University General Hospital, Tianjin, China

Submitted: 29 May 2017

Accepted: 8 July 2017

Arch Med Sci 2020; 16 (2): 253-259

DOI: https://doi.org/10.5114/aoms.2020.93341

Copyright @ 2020 Termedia \& Banach

\begin{abstract}
Introduction: The aim of the present study was to assess the efficacy of molecularly targeted agents (MTAs) in the treatment of elderly patients with metastatic oesophago-gastric cancer (mOGC).

Material and methods: We systematically searched electronic databases and abstracts presented at American Society of Clinical Oncology (ASCO) meetings up to January 31, 2017. Hazard ratios (HRs) were used to estimate overall survival (OS) and progression-free survival (PFS). Subgroup analysis and publication bias were also evaluated. All statistical analysis was conducted using Comprehensive Meta Analysis software (Version 2.0).

Results: A total of 2,149 elderly patients with mOGC from thirteen trials were included. Compared to non-MTA-containing regimens, OS was significantly improved in the MTA-containing regimens $(\mathrm{HR}=0.86,95 \% \mathrm{Cl}: 0.75-0.99$, $p=0.037$ ), but not for PFS ( $H R=1.05,95 \% \mathrm{Cl}: 0.85-1.30, p=0.67)$. In addition, subgroup analysis indicated that MTA-containing regimens as second-line therapy in elderly mOGC patients significantly improved PFS $(\mathrm{HR}=0.58 ; 95 \% \mathrm{Cl}: 0.39-0.85, p=0.005)$ and OS ( $\mathrm{HR}=0.82,95 \% \mathrm{Cl}: 0.70-$ $0.96, p=0.016)$, but did not significantly improve PFS $(\mathrm{HR}=1.36 ; 95 \% \mathrm{Cl}$ : $1.06-1.76, p=0.017)$ and OS (HR $=0.98,95 \% \mathrm{Cl}: 0.77-1.27, p=0.90)$ for MTA-containing regimens as first-line therapy in these patients. No publication bias was detected by Begg's and Egger's tests for OS and PFS.

Conclusions: Our results indicate that the MTA-containing therapies significantly improve OS but not for PFS in elderly mOGC patients. Sub-group analysis shows that improved efficacy is only observed in the second-line setting and not in the first-line setting. Our findings support the use of angiogenesis as second-line treatment for elderly mOGC patients.
\end{abstract}

Key words: oesophago-gastric cancer, elderly, systematic review, metaanalysis, targeted agents.

\section{Introduction}

Oesophago-gastric cancer (OGC) is the fourth most common malignant disease and the second leading cancer-related mortality worldwide, accounting for $8 \%$ of all new cancer cases and $10 \%$ of the total cancer deaths worldwide [1]. Substantial geographic variation exists in incidence, with the highest incidence rates occurring in Asia, South America, and Eastern Europe [2]. Based on the Surveillance, Epidemiology, and End Results (SEER) database, more than $60 \%$ of OGC cases are diagnosed at the age of 65 , and about $30 \%$ of these patients are older than

\author{
Corresponding author: \\ Qing-Hua Zhou \\ Department of Oncology \\ Tianjin Medical \\ University \\ General Hospital \\ 154 Anshan Road \\ Tianjin, China \\ Phone: +86-022-60361301 \\ Fax: +86-022-60362255 \\ E-mail: zhouqinghua2017@ \\ tom.com
}


75 years. Additionally, the elderly population is increasing worldwide, and life expectancy has also consistently increased in most countries [3]. As a result, it is urgently necessary to define the best treatment strategy for elderly mOGC patients.

Currently, most of these patients are diagnosed with locally advanced or metastatic OGC. Although chemotherapy remains the backbone of treatment for metastatic oesophago-gastric cancer (mOGC) resulting in superior survival outcomes compared with best supportive care $[4,5]$, the prognosis of mOGC patients remains poor with median survival less than 1 year. Therefore, novel treatments for mOGC are clearly needed. During the past years, the emergence of molecularly targeted agents (MTAs) has provided a new promising treatment for mOGC patients [6-8]. Currently, trastuzumab and ramucirumab have been approved by the FDA for use in mOGC patients. Additionally, several novel MTAs have been extensively assessed in clinical trials. However, due to the stringent enrolment criteria for patients in prospective trials, the enrolled elderly patients in clinical studies are not entirely representative of the overall elderly patient population. Thus, clinicians should be cautious when applying these data to the overall elderly patient population. As the elderly population increases, it is urgently necessary to define the best treatment strategy for elderly mOGC patients. In the present study, we performed a meta-analysis of prospective clinical trials to investigate the efficacy of MTAs in the treatment of mOGC in this setting.

\section{Material and methods}

\section{Selection of studies}

We searched the PubMed (data from January 2000 to January 2017), Embase (data from January 2000 to January 2017) and the Cochrane Library electronic databases for relevant articles by using the following key words: "mOGC", "gastric cancer", "gastric carcinoma", "esophagogastric carcinoma", "molecular targeted agents", "angiogenesis inhibitors", "anti-HER agents", "EGFR monoclonal anti-bodies", "randomized controlled trials" and "prospective trials". The reference lists of the retrieved articles were hand searched to identify additional relevant articles. Two authors (H.L. and L.Z.) carried out the search independently. No language restrictions were set in the search. If more than one publication was found for the same trial, the most complete, recent, and updated report of the clinical trial was included in the meta-analysis. Clinical trials that met the following criteria were included: (1) prospective randomized controlled phase II or III trials in mOGC patients (including gastric cancer or oesophagogastric carcinoma; and (2) available survival data of MTAs in elderly mOGC patients.

\section{Data extraction}

Two authors (Q.H. Z. and D.S.Z.) independently extracted the data from included trials. We conducted this meta-analysis based on the Preferred Reporting Items for Systematic review and MetaAnalysis (PRISMA) statement [9]. Disagreements between investigators were resolved by discussion and consensus. A standardized Excel file was used for data extraction. The following data were extracted: first author, publication year, the number of enrolled patients and elderly patients, median age, hazard ratios (HRs) with 95\% confidence intervals (Cls) for OS and PFS in elderly patients.

\section{Clinical end point and statistical methods}

The outcome measures of interest were progression-free survival (PFS) and overall survival (OS). We investigated the overall efficacy of MTAs in the treatment of elderly patients with mOGC based on the data from the included trials. PFS and OS were considered as time-to-event variables, and therefore were expressed as HRs with $95 \% \mathrm{Cls}$ for each study. HR > 1 reflected more deaths or progression in the MTA-containing regimen group, and vice versa. Heterogeneity across the studies was assessed using the $\chi^{2}$-based $\mathrm{Q}$ statistic [10]. The $I^{2}$ statistic was also calculated to quantitatively evaluate the degree of inconsis tency between trials. In addition, we performed subgroup analysis based on treatment line and specific drugs to investigate the sources of heterogeneity. We used the Begg and Egger tests to assess the presence of publication bias [11] Study quality was assessed using the Jadad fiveitem scale that included the randomization, double blinding, and withdrawals; the final score was reported between 0 and 5 [12]. All $p$-values of less than 0.05 were considered statistically significantly. All statistical analysis was calculated using Version 2 of the Comprehensive MetaAnalysis program (Biostat, Englewood, NJ).

\section{Results}

\section{Search results}

Our search yielded 250 clinical studies relevant to MTAs in mOGC patients. After reviewing the title or abstract, a total of 13 prospective randomized controlled trials were included for analysis, included 3 phase II [13-15] and 10 phase III RCTs [16-25]. The flowchart showing the study selection process is shown in Figure 1.

\section{Characteristics of the included studies}

In total, a total of 2,149 elderly patients were included in the present study. The characteristics of patients and studies are listed in Table I. Among 


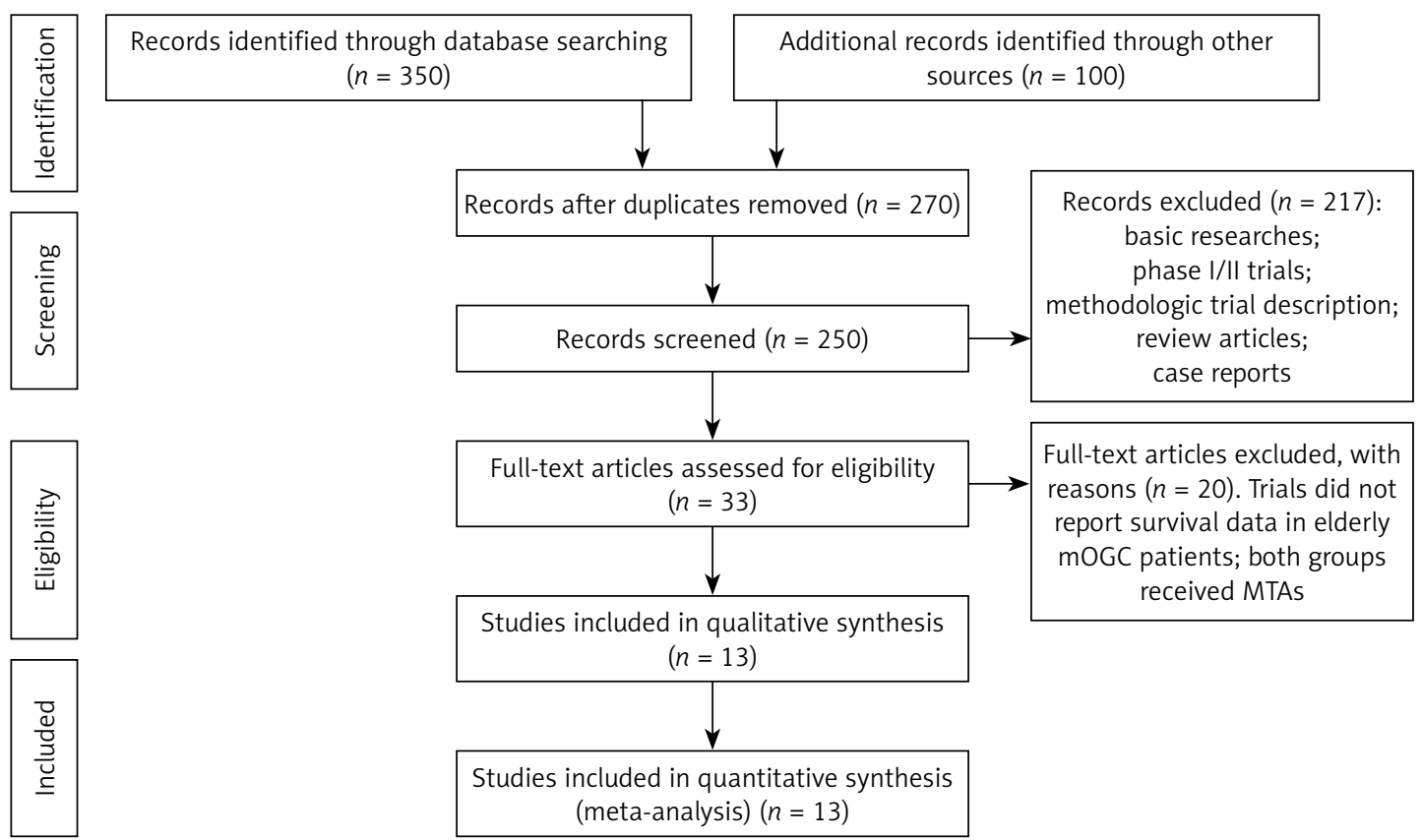

Figure 1. Studies eligible for inclusion in the meta-analysis

these studies, five trials assessed angiogenesis inhibitors in mOGC patients [15, 16, 19, 22, 24], four trials assessed anti-EGFR agents in mOGC patients $[13,14,17,18]$, three trials assessed anti-HER2 agents in mOGC patients $[20,21,25]$ and the remaining one trial investigated everolimus in mOGC patients [23]. Additionally, six trials assessed the role of MTAs as first-line treatment for mOGC patients, and the remaining seven trials in the second-line setting. The clinical characteristics were generally balanced between the intervention and control arm. The quality of each included study was roughly assessed according to the Jadad scale; the median Jadad score of the included studies was 5 (range: 3-5).

\section{Progression-free survival}

Six trials of the thirteen trials reported PFS data in the study patients. The pooled results of these studies indicated that the MTA-containing regimens did not improve PFS, giving $H R=1.05$ (95\% Cl: 0.85-1.30, $p=0.67$, Figure 2), compared with non-MTA-containing regimens. Begg's test and Egger's test revealed no evidence of obvious publication bias ( $p=0.57$ and $p=0.83$, respectively). Meanwhile, significant heterogeneity was identified $\left(R^{2}=81.5 \%, p<0.001\right)$, and the pooled HR for PFS was determined using a random-effects model. Subsequently, we performed subgroup analyses to explore potential sources of heterogeneity. Our results demonstrated that the addition of MTAs to therapies significantly improves PFS as second-line therapy $(\mathrm{HR}=0.58 ; 95 \% \mathrm{Cl}$ : 0.39$0.85, p=0.005)$ in elderly patients with mOGC, but not for first-line therapy $(\mathrm{HR}=1.36 ; 95 \% \mathrm{Cl}$ : $1.06-1.76, p=0.017)$.

\section{Overall survival}

Twelve trials of the thirteen trials reported OS data of elderly patients. The pooled results demonstrated that MTA-containing regimens significantly improve OS in comparison with non-MTA-containing regimens $(\mathrm{HR}=0.86,95 \% \mathrm{Cl}$ : $0.75-0.99, p=0.037$, Figure 3) using a random-effects model. Begg's test and Egger's test revealed no evidence of obvious publication bias ( $p=0.78$ and $p=0.94$, respectively). We also conducted sensitivity analysis to examine the stability and reliability of pooled $\mathrm{HRs}$ by sequential omission of individual studies. The results indicated that the significance estimate of pooled HRs was significantly influenced by omitting each single study conducted by Bang et al. [20], Fuchs et al. [19] and Ohtsu et al. [23] (Figure 4). We then performed sub-group analysis based on treatment line, and found that trials using MTA-containing regimens as second-line $(\mathrm{HR}=0.82,95 \% \mathrm{Cl}: 0.70-0.96$, $p=0.016)$ significantly improved OS compared to non-MTA-containing regimens, but not for first-line therapies $(\mathrm{HR}=0.98,95 \% \mathrm{Cl}$ : 0.76-1.27, $p=0.90)$. Moreover, subgroup analyses identified statistically significant improvement in OS in the subgroup of elderly mOGC patients treated with angiogenesis inhibitors ( $\mathrm{HR}=0.78,95 \% \mathrm{Cl}$ : 0.62$0.97, p=0.027$ ), while the use of anti-EGFR monoclonal antibodies $(\mathrm{HR}=1.14,95 \% \mathrm{Cl}$ : $0.90-1.44$, $p=0.27)$, anti-HER2 agents $(\mathrm{HR}=0.84,95 \% \mathrm{Cl}$ : $0.61-1.17, p=0.30)$ and mTOR inhibitors (HR = 
Table I. Baseline characteristics of 13 included randomized controlled trials

\begin{tabular}{|c|c|c|c|c|c|c|c|c|c|}
\hline Authors & $\begin{array}{l}\text { Treat- } \\
\text { ment line }\end{array}$ & Age & Treatment arms & $\begin{array}{c}\text { No. of } \\
\text { elderly } \\
\text { pa- } \\
\text { tients }\end{array}$ & $\begin{array}{l}\text { No. for } \\
\text { analy- } \\
\text { sis }\end{array}$ & $\begin{array}{c}\text { Median } \\
\text { age } \\
\text { [years] }\end{array}$ & $\begin{array}{l}\text { Median } \\
\text { PFS } \\
\text { [months] }\end{array}$ & $\begin{array}{c}\text { Median } \\
\text { OS } \\
\text { [months] }\end{array}$ & $\begin{array}{l}\text { Jadad } \\
\text { Score }\end{array}$ \\
\hline \multirow[t]{2}{*}{$\begin{array}{l}\text { Du et al., } \\
2015\end{array}$} & \multirow[t]{2}{*}{ First-line } & \multirow[t]{2}{*}{60} & $\begin{array}{l}\text { Nimotuzumab + } \\
\text { chemotherapy }\end{array}$ & 26 & 31 & 58 & 4.8 & 10.2 & 3 \\
\hline & & & Chemotherapy & & 31 & 53 & 7.2 & 14.3 & \\
\hline \multirow[t]{2}{*}{$\begin{array}{l}\text { Satoch et al., } \\
2015\end{array}$} & \multirow[t]{2}{*}{$\begin{array}{l}\text { Second- } \\
\text { line }\end{array}$} & \multirow[t]{2}{*}{65} & $\begin{array}{l}\text { Nimotuzumab + } \\
\text { chemotherapy }\end{array}$ & 32 & 40 & 60 & 2.4 & 8.3 & 3 \\
\hline & & & Chemotherapy & & 43 & 63.5 & 2.8 & 7.7 & \\
\hline \multirow{2}{*}{$\begin{array}{l}\text { Fuchs et al., } \\
2014\end{array}$} & \multirow{2}{*}{$\begin{array}{l}\text { Second- } \\
\text { line }\end{array}$} & \multirow[t]{2}{*}{65} & Ramucirumab & 128 & 236 & 60 & NR & 5.2 & 5 \\
\hline & & & Placebo & & 115 & 60 & $N R$ & 3.8 & \\
\hline \multirow[t]{2}{*}{$\begin{array}{l}\text { Wilke et al., } \\
2015\end{array}$} & \multirow[t]{2}{*}{$\begin{array}{l}\text { Second- } \\
\text { line }\end{array}$} & \multirow[t]{2}{*}{65} & $\begin{array}{l}\text { Ramucirumab } \\
8 \mathrm{mg} / \mathrm{kg}+\text { PTX }\end{array}$ & 249 & 327 & 61 & 4.4 & 9.6 & 5 \\
\hline & & & Placebo + PTX & & 329 & 61 & 2.9 & 7.4 & \\
\hline \multirow{2}{*}{$\begin{array}{l}\text { Satoch et al., } \\
2014\end{array}$} & \multirow{2}{*}{$\begin{array}{l}\text { Second- } \\
\text { line }\end{array}$} & \multirow[t]{2}{*}{65} & Lapatinib + PTX & 97 & 132 & 61 & 5.4 & 11 & 3 \\
\hline & & & PTX & & 129 & 62 & 4.4 & 8.9 & \\
\hline \multirow{2}{*}{$\begin{array}{l}\text { Waddell } \\
\text { et al., } 2013\end{array}$} & \multirow[t]{2}{*}{ First-line } & \multirow[t]{2}{*}{60} & Panitumumab + EOC & 338 & 278 & 63 & 7.4 & 11.3 & 3 \\
\hline & & & EOC & & 275 & 62 & 6 & 8.8 & \\
\hline \multirow{2}{*}{$\begin{array}{l}\text { Ohtsu et al., } \\
2013\end{array}$} & \multirow{2}{*}{$\begin{array}{l}\text { Second- } \\
\text { line }\end{array}$} & \multirow[t]{2}{*}{65} & Everolimus $10 \mathrm{mg} /$ day & 267 & 439 & 62 & 1.7 & 5.4 & 5 \\
\hline & & & Placebo & & 217 & 62 & 1.4 & 4.3 & \\
\hline \multirow[t]{2}{*}{$\begin{array}{l}\text { Lordick et al., } \\
2013\end{array}$} & \multirow[t]{2}{*}{ First-line } & \multirow[t]{2}{*}{65} & $\begin{array}{c}\text { Cetuximab + } \\
\text { capecitabine + DDP }\end{array}$ & 280 & 455 & 60 & 4.4 & 9.4 & 3 \\
\hline & & & Capecitabine + DDP & & 449 & 59 & 5.6 & 10.7 & \\
\hline \multirow[t]{2}{*}{$\begin{array}{l}\text { Bang et al., } \\
2010\end{array}$} & \multirow[t]{2}{*}{ First-line } & \multirow[t]{2}{*}{60} & $\begin{array}{l}\text { Trastuzumab + } \\
\text { chemotherapy }\end{array}$ & 305 & 294 & 59.4 & 6.7 & 13.8 & 3 \\
\hline & & & Chemotherapy & & 290 & 58.5 & 5.5 & 11.1 & \\
\hline \multirow{2}{*}{$\begin{array}{l}\text { Li et al., } \\
2016\end{array}$} & \multirow{2}{*}{$\begin{array}{l}\text { Second- } \\
\text { line }\end{array}$} & \multirow[t]{2}{*}{65} & Apatinib & 37 & 176 & 58 & 2.6 & 6.5 & 5 \\
\hline & & & Placebo & & 91 & 58 & 1.8 & 4.7 & \\
\hline \multirow{2}{*}{$\begin{array}{l}\text { Hecht et al., } \\
2016\end{array}$} & First-line & 60 & Lapatinib + CapeOx & 251 & 249 & 61 & 6 & 12.2 & 5 \\
\hline & & & Placebo + CapeOx & & 238 & 59 & 5.4 & 10.5 & \\
\hline Pavlakis N. & Second- & 60 & Regorafenib & 85 & 97 & 63 & 2.6 & NR & 5 \\
\hline & & & Placebo & & 50 & 62 & 1.8 & NR & \\
\hline $\begin{array}{l}\text { Yoon et al., } \\
2016\end{array}$ & First-line & 65 & $\begin{array}{l}\text { Ramucirumab + } \\
\text { FOLFOX }\end{array}$ & 54 & 84 & 64.5 & 6.4 & 11.7 & 5 \\
\hline & & & Placebo + FOLFOX & & 84 & 60 & 6.7 & 11.5 & \\
\hline
\end{tabular}

OS - overall survival, PFS - progression-free survival, PTX - paclitaxel, DDP - cisplatin, EOC - epirubicin + oxaliplatin + capecitabine, CapeOx - capecitabine + oxaliplatin, FOLFOX - oxaliplatin + leucovorin + 5-fluorouracil.

$0.83,95 \% \mathrm{Cl}: 0.63-1.10, p=0.19)$ did not significantly improve OS compared to controls.

\section{Discussion}

In the past years, the introduction of novel agents targeting specific growth and survival pathways represents the most promising treatment strategy to improve outcome for patients with mOGC [26]. A previous meta-analysis conducted by Ciliberto et al. [27] showed that the use of targeted agents significantly improved survival (OS: $H R=0.823$; PFS: $H R=0.762$ ) compared to conventional treatments in advanced gastric cancer patients, and it did not increase severe toxicities related to MTAs. Recently, Jemal et al. [28] also found that there was a significant survival benefit 


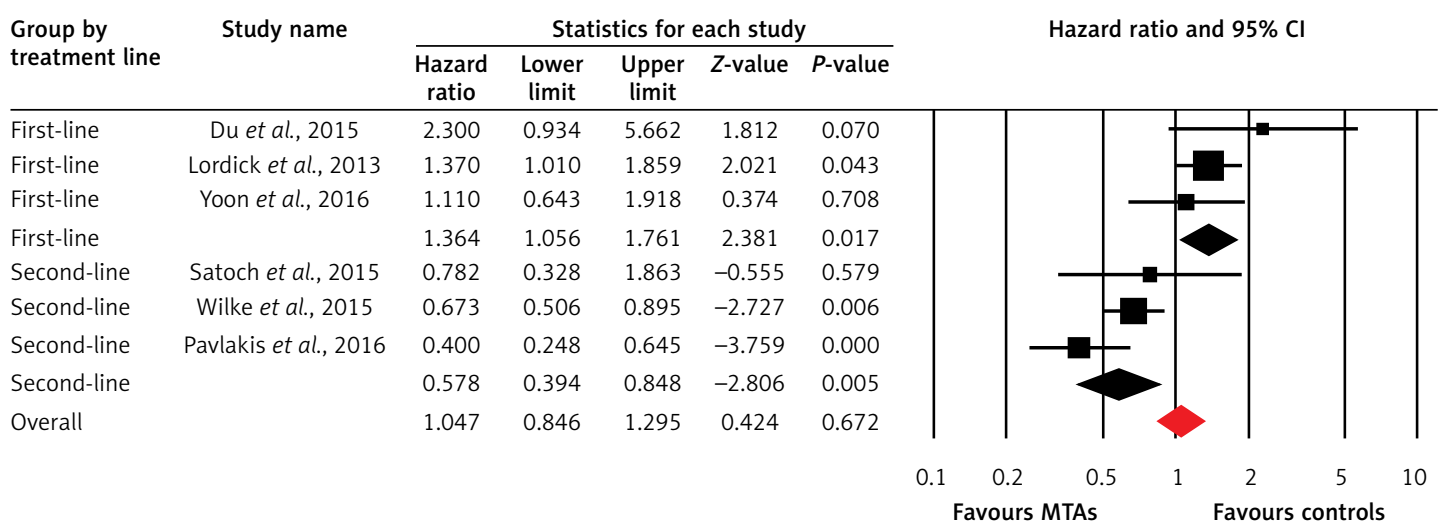

Figure 2. Random-effects model of hazard ratio $(95 \% \mathrm{Cl})$ of OS associated with therapies with or without MTAs

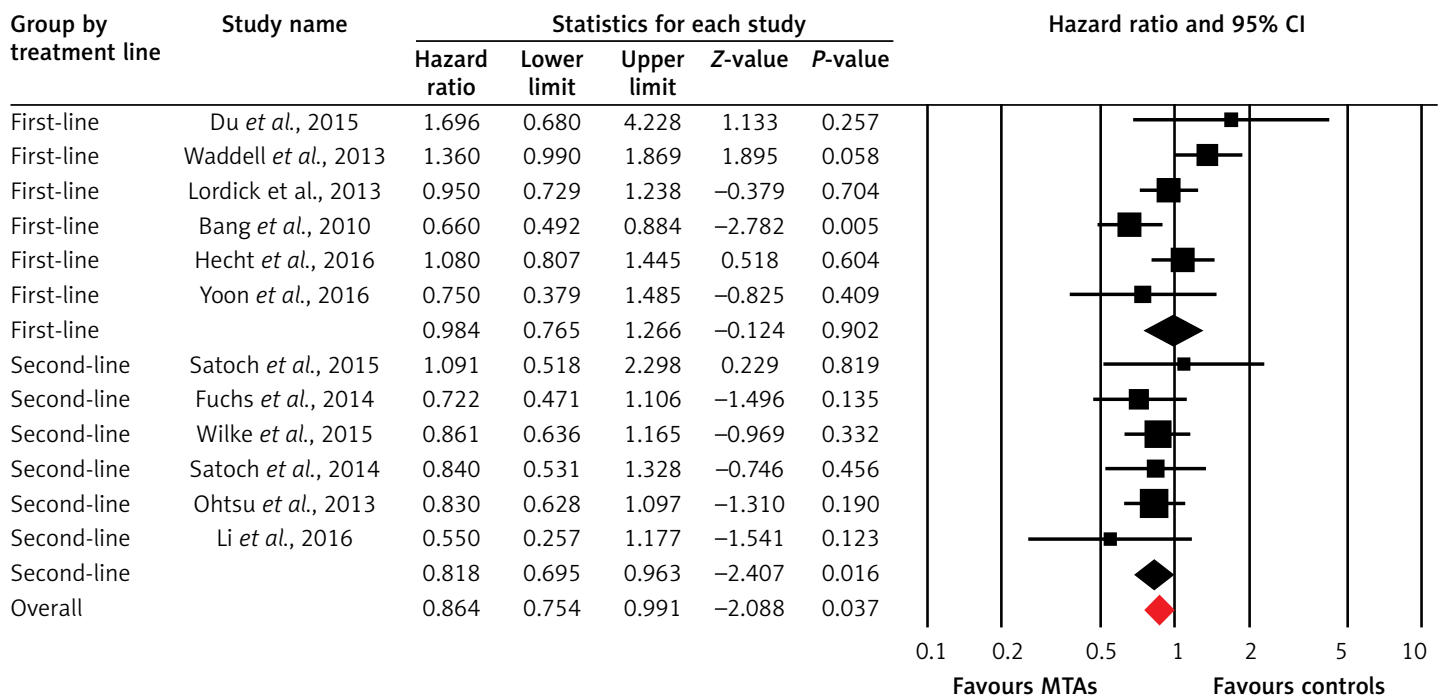

Figure 3. Random-effects model of hazard ratio $(95 \% \mathrm{Cl})$ of PFS associated with therapies with or without MTAs

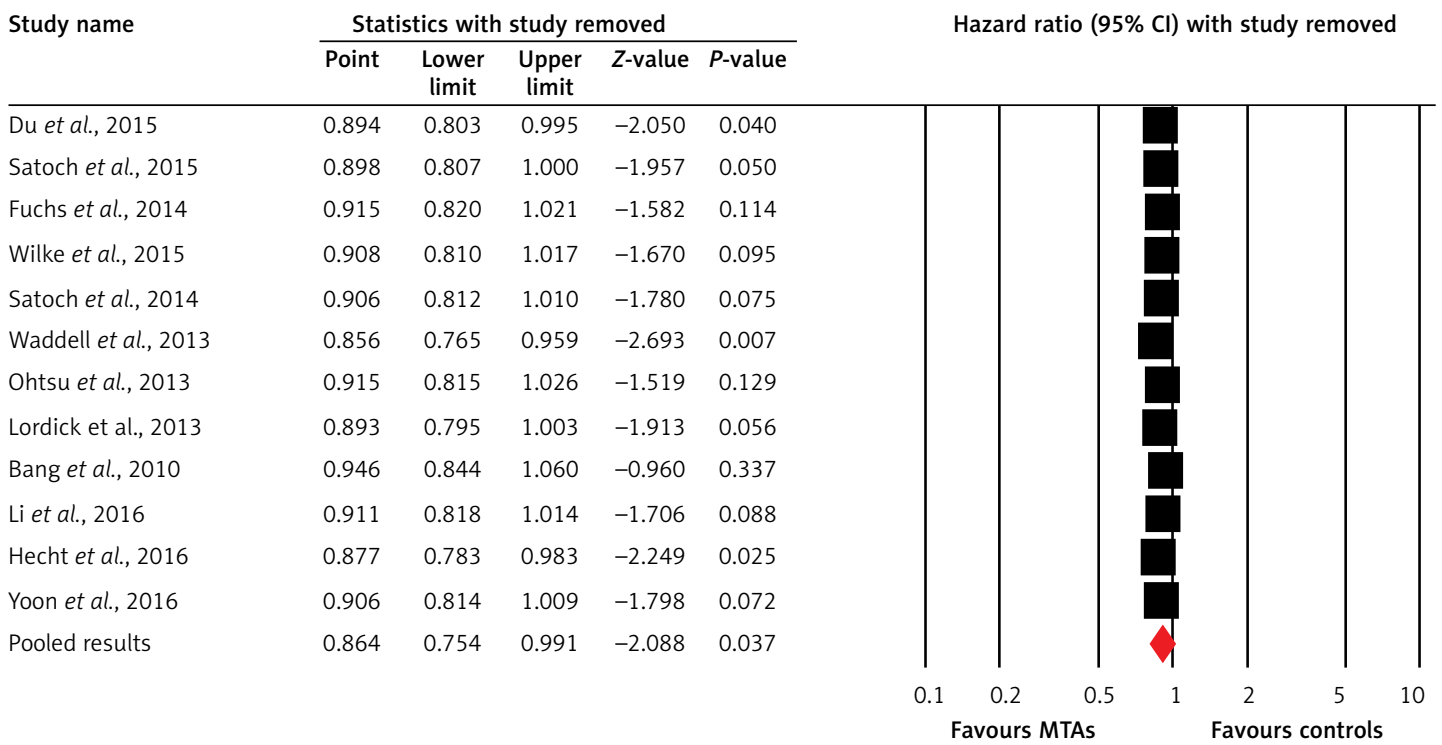

Figure 4. Meta-analysis of hazard ratio of OS associated with MTA-containing regimen versus control: 'leave-oneout' sensitivity analysis 
with targeted agents in gastric cancer patients $(\mathrm{HR}=0.88,95 \% \mathrm{Cl}: 0.79-0.99, p=0.032) \mathrm{com}-$ pared to controls. However, there are limited data specifically focusing on the efficacy of targeted agents in elderly patients with mOGC. As a result, we performed the present study to investigate the overall efficacy of MTAs in the treatment of elderly mOGC patients.

Our systematic review is, as far as we know, the first systematic review to specially assess the efficacy of MTAs in the treatment of elderly mOGC patients. Our study included a total of 2,149 elderly patients with mOGC from thirteen RCTs. Our results demonstrate that MTA-containing treatment shows promise as being effective for elderly mOGC patients in terms of OS. However, there is significant heterogeneity among included studies when analyzing the above endpoints. One possible explanation for this heterogeneity is that our study pooled studies across different lines of therapy investigating MTAs with different modes of action (ramucirumab, lapatinib, regorafenib, nimotuzumab, panitumumab, and cetuximab). This explanation is confirmed by the observation that heterogeneity among trials becomes non-significant when pooling the results according to treatment line and targeted agents. Pre-defined subgroup analyses indicate that the most consistent survival benefit is found when MTAs are used in second-line treatment for these patients. Additionally, greater OS benefit is observed in elderly mOGC patients treated with angiogenesis inhibitors compared to anti-EGFR monoclonal antibodies, anti-HER2 agents and mTOR inhibitors. One possible explanation for this finding is that several angiogenesis inhibitors have been proven to improve outcome of previously treated mOGC patients. Indeed, two angiogenesis inhibitors, regorafenib and ramucirumab, have been approved by the FDA as second-line treatment for the treatment of mOGC patients. However, no other MTAs, except for anti-HER2 agents, have been approved for the treatment of mOGC patients. Therefore, our findings further confirm that the effect of angiogenesis inhibitors on OS is not different in younger and older patients undergoing second-line treatment. Angiogenesis inhibitors could be recommended as second-line treatment for elderly mOGC patients.

Several limitations exist in this analysis. First of all, this is a meta-analysis at the study level. We could not obtain individual patient data from the publications; thus we could not incorporate patients' variables into the analysis. Second, there is considerable heterogeneity among the included studies, because different targeted agents are included for analysis, although we pooled subgroup analysis according to treatment line and regimens. Furthermore, it remains undetermined which targeted agent would be the best choice for elderly mOGC patients. Finally, as positive clinical trials are more likely to be published than negative clinical trials, clinicians should pay more attention to publication bias in meta-analyses of published studies. In the present meta-analysis, we detected no publication bias using Begg and Egger tests for OS and PFS.

In conclusion, the findings of this study suggest that the MTA-containing therapies significantly improve OS but not for PFS in elderly mOGC patients. Improved efficacy is only observed in the second-line setting and not in the first-line setting. Greater OS benefit is observed in elderly $\mathrm{mOGC}$ patients treated with angiogenesis in hibitors compared to anti-EGFR monoclonal antibodies, anti-HER2 agents and mTOR inhibitors. Our findings support the use of angiogenesis as second-line treatment for elderly mOGC patients.

\section{Conflict of interest}

The authors declare no conflict of interest.

\section{References}

1. Santoni M, Conti A, Andrikou K, et al. Risk of pruritus in cancer patients treated with biological therapies: a systematic review and meta-analysis of clinical trials. Crit Rev Oncol Hematol 2015; 96: 206-19.

2. Davidson M, Okines AF, Starling N. Current and future therapies for advanced gastric cancer. Clin Colorectal Cancer 2015; 14: 239-250.

3. Kim HS, Kim JH, Kim JW, Kim BC. Chemotherapy in elderly patients with gastric cancer. J Cancer 2016; 7: 88-94.

4. Kim HS, Kim HJ, Kim SY, et al. Second-line chemotherapy versus supportive cancer treatment in advanced gastric cancer: a meta-analysis. Ann Oncol 2013; 24: 2850-4.

5. Janowitz T, Thuss-Patience P, Marshall A, et al. Chemotherapy vs supportive care alone for relapsed gastric, gastroesophageal junction, and oesophageal adenocarcinoma: a meta-analysis of patient-level data. Br J Cancer 2016; 114: 381-7.

6. Tomasello G, Ghidini M, Liguigli W, Ratti M, Toppo L, Passalacqua $R$. Targeted therapies in gastric cancer treatment: where we are and where we are going. Invest New Drugs 2016; 34: 378-93.

7. Yazici O, Sendur MA, Ozdemir N, Aksoy S. Targeted therapies in gastric cancer and future perspectives. World J Gastroenterol 2016; 22: 471-89.

8. Huang L, Liu Z, Deng D, et al. Anti-epidermal growth factor receptor monoclonal antibody-based therapy for metastatic colorectal cancer: a meta-analysis of the effect of PIK3CA mutations in KRAS wild-type patients. Arch Med Sci 2014; 10: 1-9.

9. Moher D, Cook DJ, Eastwood S, Olkin I, Rennie D, Stroup DF. Improving the quality of reports of meta-analyses of randomised controlled trials: the QUOROM statement. Quality of reporting of meta-analyses. Lancet 1999; 354: 1896-900.

10. Zintzaras E, loannidis JP. Heterogeneity testing in meta-analysis of genome searches. Genet Epidemiol 2005; 28: 123-37. 
11. Vandenbroucke JP. Bias in meta-analysis detected by a simple, graphical test. Experts' views are still needed. BMJ 1998; 316: 469-70.

12. Zhou F, Jiang T, Ma W, Gao G, Chen X, Zhou C. The impact of clinical characteristics on outcomes from maintenance therapy in non-small cell lung cancer: a systematic review with meta-analysis. Lung Cancer 2015; 89: 203-11.

13. Du F, Zheng Z, Shi S, et al. S-1 and cisplatin with or without nimotuzumab for patients with untreated unresectable or metastatic gastric cancer: a randomized, open-label phase 2 trial. Medicine 2015; 94: e958.

14. Satoh T, Lee KH, Rha SY, et al. Randomized phase II trial of nimotuzumab plus irinotecan versus irinotecan alone as second-line therapy for patients with advanced gastric cancer. Gastric Cancer 2015; 18: 824-32.

15. Yoon HH, Bendell JC, Braiteh FS, et al. Ramucirumab combined with FOLFOX as front-line therapy for advanced esophageal, gastroesophageal junction, or gastric adenocarcinoma: a randomized, double-blind, multicenter phase II trial. Ann Oncol 2016; 27: 2196-203.

16. Wilke H, Muro K, Van Cutsem E, et al. Ramucirumab plus paclitaxel versus placebo plus paclitaxel in patients with previously treated advanced gastric or gastro-oesophageal junction adenocarcinoma (RAINBOW): a double-blind, randomised phase 3 trial. Lancet Oncol 2014; 15: 1224-35.

17. Waddell T, Chau I, Cunningham D, et al. Epirubicin, oxaliplatin, and capecitabine with or without panitumum$a b$ for patients with previously untreated advanced oesophagogastric cancer (REAL3): a randomised, openlabel phase 3 trial. Lancet Oncol 2013; 14: 481-9.

18. Lordick F, Kang YK, Chung HC, et al. Capecitabine and cisplatin with or without cetuximab for patients with previously untreated advanced gastric cancer (EXPAND): a randomised, open-label phase 3 trial. Lancet Oncol 2013; 14: 490-9.

19. Fuchs CS, Tomasek J, Yong CJ, et al. Ramucirumab monotherapy for previously treated advanced gastric or gastro-oesophageal junction adenocarcinoma (REGARD): an international, randomised, multicentre, placebo-controlled, phase 3 trial. Lancet 2014; 383: 31-9.

20. Bang YJ, Van Cutsem E, Feyereislova A, et al. Trastuzum$a b$ in combination with chemotherapy versus chemotherapy alone for treatment of HER2-positive advanced gastric or gastro-oesophageal junction cancer (ToGA): a phase 3, open-label, randomised controlled trial. Lancet 2010; 376: 687-97.

21. Satoh T, Xu RH, Chung HC, et al. Lapatinib plus paclitaxel versus paclitaxel alone in the second-line treatment of HER2-amplified advanced gastric cancer in Asian populations: TyTAN: a randomized, phase III study. J Clin Oncol 2014; 32: 2039-49.

22. Pavlakis N, Sjoquist KM, Martin AJ, et al. Regorafenib for the treatment of advanced gastric cancer (INTEGRATE): a multinational placebo-controlled phase II trial. J Clin Oncol 2016; 34: 2728-35.

23. Ohtsu A, Ajani JA, Bai YX, et al. Everolimus for previously treated advanced gastric cancer: results of the randomized, double-blind, phase III GRANITE-1 study. J Clin Oncol 2013; 31: 3935-43.

24. Li J, Qin S, Xu J, et al. Randomized, double-blind, placebo-controlled phase III trial of apatinib in patients with chemotherapy-refractory advanced or metastatic adenocarcinoma of the stomach or gastroesophageal junction. J Clin Oncol 2016; 34: 1448-54.

25. Hecht JR, Bang YJ, Qin SK, et al. Lapatinib in combination with capecitabine plus oxaliplatin in human epidermal growth factor receptor 2-positive advanced or metastatic gastric, esophageal, or gastroesophageal adenocarcinoma: TRIO-013/LOGiC--a randomized phase III trial. J Clin Oncol 2016; 34: 443-51.

26. Wang Z, Hao B, Yang Y, Wang R, Li Y, Wu Q. Prognostic role of SPARC expression in gastric cancer: a meta-analysis. Arch Med Sci 2014; 10: 863-9.

27. Ciliberto D, Staropoli N, Caglioti F, et al. A systematic review and meta-analysis of randomized trials on the role of targeted therapy in the management of advanced gastric cancer: evidence does not translate? Cancer Biol Ther 2015; 16: 1148-59.

28. Jemal A, Bray F, Center MM, Ferlay J, Ward E, Forman D. Global cancer statistics. CA Cancer J Clin 2011; 61: 69-90. 